\title{
Comparison of Trachlight ${ }^{\mathrm{TM}}$ guided tracheal intubation in the lateral position versus the supine position
}

\author{
*Manish Naithani ${ }^{1}$, Kirti N Saxena, C K Dua, Prachi Gaba \\ Consultant ${ }^{1}$, Department of Anaesthesiology and Intensive Care, Maulana Azad Medical College and \\ Associated Hospitals, New Delhi, India \\ *Corresponding Author: drmanishnaithani@gmail.com
}

Keywords: anaesthetic technique, lightwand; intubation, tracheal; patient positioning, lateral

\begin{abstract}
Background:
Lighted stylets have established their place as an important armament in the management of both uncomplicated as well as difficult airways. Most of the investigators have worked on patients in supine position, though intubation in the lateral position might be necessary sometimes. This study evaluated the Trachlight ${ }^{\mathrm{TM}}$ for intubation of patients in the lateral position.
\end{abstract}

\section{Method:}

Seventy ASA I-II patients scheduled for elective surgeries were randomly allocated into two groups of 35 patients each. The Groups T1 and T2 consisted of patients who were intubated with the Trachlight ${ }^{\mathrm{TM}}$ in the supine and lateral positions, respectively. The comparison of the two positions was based on: success of intubation, success at first attempt, number of attempts, intubation time, and incidences of oesophageal intubation, oxygen desaturation, mucosal injury and postoperative sore throat.

\section{Results:}

The overall intubation success rate was comparable at $100 \%$ in the supine and $97.14 \%$ in the lateral position. The success rate of intubation in the first attempt was $91.42 \%$ in the supine, and $88.57 \%$ in the lateral position, and was comparable, as was the average intubation time. The incidence of intra and post-operative complications was low, and was comparable in both the positions.

\section{Conclusion:}

These results suggest that the Trachlight ${ }^{\mathrm{TM}}$ is a useful intubating device in challenging situations like the lateral position, and should be used frequently in routine cases to gain expertise. We think that using 'LMA Fastrach ${ }^{\mathrm{TM}}$ tubes', with their soft, moulded tips contributed to the short intubation time and minimal trauma.

\section{Introduction}

Traditional training in tracheal intubation is done in the supine position. Tracheal intubation in the lateral position is a challenging task and requires expertise and experience. ${ }^{1}$ Some instances where intubation in lateral position might be required are failed regional anaesthesia midway through a prolonged surgery, accidental extubation in patients being operated in the lateral position, morbidly obese patients, ${ }^{2}$ certain congenital syndromes, large tumour on the back, amongst others. Though direct laryngoscopy remains the preferred method for intubation due to its ease and familiarity, it does require more number of attempts in the lateral position, ${ }^{1}$ and hence, more and more devices are being explored for this purpose.

Cheng and colleagues used the Trachlight ${ }^{\mathrm{TM}}$ (Laerdal Medical, Armonk, NY, USA) for tracheal intubation of patients in the supine, right and left lateral positions and found little difference in the success rates in the three positions. ${ }^{3}$

Despite extensive net search, very limited related literature could be gathered. This study does a comparative evaluation of Trachlight $^{\mathrm{TM}}$ guided intubation in the lateral and supine positions based on multiple parameters.

Methods 
After approval by the Institutional Review Board of our hospital, this study included 70 ASA I-II patients, aged 18-60 years, who were scheduled to undergo general anaesthesia with endotracheal intubation for various elective surgical procedures. All patients were subjected to a detailed pre-anaesthetic check-up, and those with increased risk of pulmonary aspiration, raised intra-cranial tension, anticipated airway difficulty, and co-existing cardiovascular and respiratory disorders were excluded from the study. The criteria for difficult intubation were taken as: BMI $>$ 30, Mallampati class (MPC) III- IV, Interincisor gap $<4 \mathrm{cms}$, previous history of difficult intubation, and history of previous laryngeal or pharyngeal surgery. The patients were allocated by simple random sampling to two groups $\mathrm{T} 1$ and $\mathrm{T} 2$, of 35 patients each, which consisted of patients who were intubated with the Trachlight ${ }^{\mathrm{TM}}$ in the supine and lateral positions respectively. All patients gave written informed consent, and were fasting for at least 8 hours before surgery.

In the operation theatre, standard monitors were attached and intra-venous access established. All patients were given midazolam $20 \mu \mathrm{g} \mathrm{kg}^{-1}$ and glycopyrrolate $4 \mu \mathrm{g} \mathrm{kg}^{-1}$, before anaesthesia induction. Anaesthesia was induced with fentanyl $2 \mu \mathrm{g} \mathrm{kg}^{-1}$ and propofol $2 \mathrm{mg} \mathrm{kg}^{-1}$. Neuro-muscular blockade was provided with vecuronium $0.1 \mathrm{mg}$ $\mathrm{kg}^{-1}$ and bag and mask ventilation (BMV) was provided for 3 minutes before intubation was attempted. Anaesthesia was maintained with $1.6 \%$ isoflurane and $66 \%$ nitrous oxide in oxygen. Patients of group T2 were given an extra headring to maintain axial alignment in lateral position. The Trachlight ${ }^{\mathrm{TM}}$ was preloaded with a 'LMA Fastrach ${ }^{\mathrm{TM}}$ endo-tracheal tube' (flexometallic, silicone) having a soft, moulded tip. A size $8 \mathrm{~mm}$ ID tube was used for men and size 7 $\mathrm{mm}$ for women. To overcome bias due to the learning curve, the first author, who had used the device more than 30 times previously, performed all procedures. The investigator also had sufficient practice of tracheal intubation with the Trachlight $^{\mathrm{TM}}$ in the lateral position with the manikin prior to the study.

In both groups, after stopping BMV, the ambient OT light was reduced and the Trachlight ${ }^{\mathrm{TM}}$-tube assembly inserted through the right angle of the mouth. On reaching the oro-pharynx, the tip of the Trachlight $^{\mathrm{TM}}$-tube assembly was redirected towards midline. The glow of light and bulge in the neck was continuously looked out for.

If a faint glow was seen above the thyroid prominence, it indicated that the tip of the Trachlight ${ }^{\mathrm{TM}}$-tube assembly was located in the glosso-epiglottic fold. If the Trachlight ${ }^{\mathrm{TM}}$-tube assembly entered the oesophagus, no glow could be detected. A bright glow detected in the lateral aspect of the larynx indicated that the tip was in the pyriform fossae, which required a redirection to the midline. When the tip entered the glottic opening, a well-defined circumscribed glow could be seen in the anterior neck slightly below the thyroid prominence. The stylet was then retracted, and the Trachlight ${ }^{\mathrm{TM}}$-tube assembly advanced till the glow disappeared below the supra-sternal notch, followed by removal of the Trachlight ${ }^{\mathrm{TM}}$ from the endotracheal tube. The correct placement of the endotracheal tube was confirmed by auscultation and capnography.

Rescue BMV was provided if the oxygen saturation, as measured on the pulse oximeter, fell less than $92 \%$. Tracheal intubation was considered a failure if it could not be accomplished within three minutes of cessation of BMV. The patients with failed intubation had their trachea intubated after direct laryngoscopy in supine position.

The comparison of the two positions was based on: success at first attempt, number of intubation attempts, intubation time (time taken from the cessation of BMV to the appearance of capnographic trace through the tracheal tube with positive pressure ventilation), frequency of oesophageal intubation, incidence of oxygen desaturation (a decrease in $\mathrm{SpO}_{2}<92 \%$ on the pulse oximeter), and mucosal injury (blood staining of the device seen after withdrawal). Every time the device was taken out of the mouth, or if there was oesophageal intubation, it was counted as an attempt. All time durations were measured on a stopwatch. All patients were followed up 24 hours after surgery for any complaints of sore throat.

\section{Statistical Analysis}

Assuming the overall intubation success rate in the supine group would be at least $95 \%,{ }^{3,4}$ we decided that a $25 \%$ difference in overall intubation success rate between the groups would be clinically important. Following the Power 
method for sample size calculation for comparison of two proportions, the calculated

sample size for each arm was 35 with an alpha error of 0.05 and power of $80 \%$.

The data was analyzed, and for comparison of mean between two groups, unpaired student " $\mathrm{t}$ "test was applied. $\chi^{2}$-test or Fischer exact test were applied for categorical variables like number of attempts, incidence of mucosal injury etc.

\section{Results}

Our study included 70 patients who were divided into two groups T1 and T2. Group T1 acted as control for group T2. There were no statistically significant differences between the two groups with respect to mean age, BMI (Table 1), success of intubation, intubation in first attempt, average number of attempts, average intubation time (Table 2), and intra and post-operative complications (Table 3). All patients in supine position (100\%), and all except one patient in the lateral position $(97.14 \%)$ could be intubated successfully. The success rate of intubation in the first attempt in the supine and lateral positions, was $91.42 \%$ and $88.57 \%$, respectively, and was comparable. The average number of attempts required for intubation with the Trachlight ${ }^{\mathrm{TM}}$, which was 1.085 in the supine position and 1.088 in the lateral position, was comparable between the two groups, and was not statistically significant.

Table 1: Comparison of patient - characteristics of Groups T1 and T2

\begin{tabular}{|lll|}
\hline Parameters & T1 & T2 \\
Mean age & 30.80 & 28.51 \\
& \pm & \pm \\
Mean BMI $\left(\mathrm{kg} \cdot \mathrm{m}^{-2}\right)$ & $10.28^{*}$ & $6.09^{*}$ \\
& 21.28 & 20.94 \\
& \pm & \pm \\
& $2.66^{*}$ & $2.60^{*}$ \\
\hline
\end{tabular}

Table 2:

Comparison of intubation - characteristics of Groups T1 and T2

\begin{tabular}{|lccc|}
\hline Parameters & T1 & T2 & $\begin{array}{c}\text { P } \\
\text { value }\end{array}$ \\
\hline Successful intubation & $100 \%$ & $97.14 \%$ & 0.555 \\
Success at first attempt & $91.42 \%$ & $88.57 \%$ & 0.690 \\
$\begin{array}{l}\text { Average number of } \\
\text { attempts }\end{array}$ & $1.09 \pm 0.284^{*}$ & $1.14 \pm$ & 0.602 \\
& & $0.430^{*}$ & \\
\hline
\end{tabular}

Table 3:

Comparison of complications of Groups T1 and T2

\begin{tabular}{|lccc|}
\hline Parameters & T1 & T2 & $\begin{array}{c}\text { P } \\
\text { value }\end{array}$ \\
\hline $\begin{array}{l}\text { Incidence of oesophageal } \\
\text { intubation } \\
\text { Incidence of desaturation }\end{array}$ & $2.9 \%$ & $2.9 \%$ & 0.999 \\
Incidence of mucosal injury & $8.57 \%$ & $11.43 \%$ & 0.69 \\
Incidence of post-op sore throat & $0 \%$ & $2.9 \%$ & 0.314 \\
& $0 \%$ & $0 \%$ & 0.999 \\
\hline
\end{tabular}

Table 4:

Comparison of average intubation time of Groups T1 and $\mathrm{T} 2$

\begin{tabular}{|lccc|}
\hline Parameters & T1 & T2 & $\begin{array}{c}\text { P } \\
\text { value }\end{array}$ \\
\hline $\begin{array}{l}\text { Average intubation time } \\
\text { (seconds) }\end{array}$ & $37.69 \pm 14.65^{*}$ & $46.26 \pm$ & 0.111 \\
& & $27.66^{*}$ & \\
\hline
\end{tabular}

*- Mean \pm SD

In our study we found that intubation with the Trachlight $^{\mathrm{TM}}$ in both the supine and lateral positions could be accomplished in comparable time, with the average intubation time being 37.69 seconds in the supine position and 46.26 seconds in the lateral position.

One patient (2.9\%) had oesophageal intubation in each of the groups. There were 4 cases $(11.4 \%)$ of oxygen desaturation in the $\mathrm{T} 2$ group and 3 $(8.57 \%)$ in the $\mathrm{T} 1$ group, which was comparable. Only 1 case $(2.9 \%)$ had mucosal bleeding in T2 group as compared to none in the $\mathrm{T} 1$ group $(0 \%)$, the difference being insignificant. None of the patients in groups $\mathrm{T} 1$ and $\mathrm{T} 2$ complained of postoperative sore throat after 24 hours of extubation.

\section{Discussion}

Lighted intubation stylets have been in use since a long time for intubation of patients in the supine position. Hung and team performed a clinical trial with Trachlight ${ }^{\mathrm{TM}}$ in which nine hundred and fifty patients (479 in the Trachlight ${ }^{\mathrm{TM}}$ group and 471 in the laryngoscope group) were studied. ${ }^{4}$ There was $1 \%$ failure rate with the Trachlight ${ }^{\mathrm{TM}}$, and $92 \%$ of intubations were successful on the first attempt, compared with a $3 \%$ failure rate and an $89 \%$ success rate on the first attempt with the laryngoscope. The time to tracheal intubation was significantly less with the Trachlight ${ }^{\mathrm{TM}}$ compared with the laryngoscope $(15.7 \pm 10.8$ vs. $19.6 \pm 23.7$ $\mathrm{s})$. There were significantly fewer traumatic events in the Trachlight ${ }^{\mathrm{TM}}$ group than in the 
laryngoscope group (10 vs. 37). More patients complained of sore throat in the laryngoscope group than in the Trachlight ${ }^{\mathrm{TM}}$ group $(25.3 \%$ vs. $17.1 \%)$. Cheng and colleagues published the comparison of the supine and lateral positions for intubation with the Trachlight ${ }^{\mathrm{TM}}$. They reported a $100 \%$ success rate of intubation in the supine, right lateral and left lateral positions. The success rate of intubation in the first attempt was $90 \%$ for the supine position, and $92.5 \%$ for both the lateral positions. The average numbers of attempts were $1.1,1.075$ and 1.1 in the supine, left lateral and right lateral positions, respectively. The average intubation time (time from the insertion of the device into the mouth to its removal from the mouth) was 13.3 seconds in the left lateral position and 15.5 seconds in the right lateral position.

Our success rate of $100 \%$ in the supine position is the same as that recorded by Hung and team, and Cheng and colleagues. The success rate in the lateral position (97.14\%) also compares well with the $100 \%$ result shown by Cheng and colleagues. Successful intubation in the first attempt was not achieved in 3 patients in the supine position. In one patient, a bright glow was observed despite the tip of the tube being in the oesophagus. The other two patients revealed a Cormack-Lehane Grade III view on laryngoscopy. Successful intubation in the first attempt was not achieved in four patients in the lateral position. Three patients required 2 attempts while one had a failed intubation as mentioned before. One of the patients had her hair tied in a bun, which was stuck in the hollow of the head-ring impeding the extension of the neck. Direct laryngoscopy performed at the time of extubation revealed Cormack-Lehane Grade III laryngoscopic views in the other two patients. The success rate of intubation in the first attempt in the supine position $(91.42 \%)$ is similar to that recorded by Hung and team (92\%) and Cheng and colleagues $(90 \%)$; that in the lateral position $(88.57 \%)$ is also comparable to the results of the study by Cheng and colleagues $(92.5 \%)$. The average number of attempts required for intubation, which was 1.085 in the supine position and 1.088 in the lateral position, was comparable to that recorded by Cheng and colleagues (1.1 and 1.075 respectively).

We found that intubation with the Trachlight ${ }^{\mathrm{TM}}$ in both the supine and lateral positions could be accomplished in comparable time (37.69 and
46.26 seconds). Our results differ from those of Cheng and colleagues, because of different definitions of intubation time. In their study, the duration of each intubation attempt was recorded as the time from the introduction of the intubation unit into the oral cavity to the time of wand removal from the tracheal tube. We calculated the intubation time from stopping of BMV till appearance of a capnographic trace on the monitor, which reflected the actual apnoea time.

One patient (2.9\%) had oesophageal intubation in each of the groups. The patient in the group T2 had a failed intubation. The patient in the group T1 had a bright glow coming through the oesophagus, which was mistaken for tracheal placement. The low incidence of oesophageal intubation with the Trachlight ${ }^{\mathrm{TM}}$ in the lateral position might be because of the fact that the tongue does not fall backwards to push the device posteriorly in the lateral position. There were 4 cases $(11.4 \%)$ of oxygen desaturation in the $\mathrm{T} 2$ group and $3(8.57 \%)$ in the $\mathrm{T} 1$ group, which was comparable. The incidence of traumatic events as seen by Hung and team with the Trachlight ${ }^{\mathrm{TM}}$ in the supine position $(2 \%)$, is similar to that seen in our study in the supine $(0 \%)$ and in the lateral position $(2.9 \%)$. None of the patients in groups T1 and $\mathrm{T} 2$ complained of post-operative sore throat after 24 hours of extubation.

Before concluding, we would like to highlight that for intubation in the lateral position, only a limited number of airway devices have been explored as yet. We used the Trachlight ${ }^{\mathrm{TM}}$ for tracheal intubation in the lateral position and found that the results were comparable to the supine position for all the parameters we studied. We postulate that the 'LMA Fastrach ${ }^{\mathrm{TM}}$ endotracheal tube', with its smooth tracheal cuff and soft, moulded tip, which we used for our study, translated into a lesser incidence of mucosal injury or post-operative sore throat. Also, because of the unique bevel and opaque sides of the tip of the Fastrach $^{\mathrm{TM}}$ tube, the glow was focused directly in front of the tube and hence chances of misinterpretation of the tip location were less. This was reflected in the short time for intubation ( $<1$ minute) in both the positions. We wholeheartedly recommend a wider use of the Trachlight $^{\mathrm{TM}}$ for tracheal intubation in the lateral position, especially along with the Fastrach ${ }^{\mathrm{TM}}$ tube. We do feel that having a single investigator was a potential source of bias, but realizing that multiple investigators with inadequate experience 
would also have affected the results predictably, we decided to persist with the former plan.

\section{References}

1. McCaul CL, Harney D, Ryan M, et al. Airway management in the lateral position: A Randomized Controlled Trial. Anesth Analg 2005; 101: 1221-5.

2. Aono J, Ueda K, Ueda W, Manabe M. Induction of anesthesia in the lateral decubitus position in morbidly obese patients. $B r J$ Anaesth 1999; 83: 356.

3. Cheng KI, Chu KS, Chau SW, et al. Lightwand assisted intubation of patients in the lateral position. Anesth Analg 2004; 99: 279-83.

4. Hung OR, Pytka S, Morris I, et al. Lightwand intubation: II-Clinical trial of a new Lightwand device for tracheal intubation in patients with difficult airways. Can J Anesth 1995; 42: 826-30.

*******************************************************************

\section{THE COLLEGE OF ANAESTHESIOLOGISTS OF SRI LANKA}

\section{LECTURE DEMONSTRATION \& CERTIFICATION \\ ON}

\section{Cardio Pulmonary Resuscitation}

$\begin{array}{ccc}\text { Venue } & - & \text { Trauma Lecture Hall } \\ \text { Date } & & \text { National Hospital, Sri Lanka } \\ \text { Time } & - & \text { on Tuesdays } \\ & 9.00 \text { am } \\ & \text { Conducted by } \\ \text { Dr Manjula Kularatne } \\ \text { Consultant Anaesthetist, NSU } \\ \text { Contact } \\ \text { Ms Chamila Gamage, } \\ \text { Office Secretary, 2672327 }\end{array}$

$* * * * * * * * * * * * * * * * * * * * * * * * * * * * * * * * * * * * * * * * * * * * * * * * * * * * * * * * * * * * *$ 